\title{
A DIGNIDADE DA PESSOA HUMANA NO SISTEMA CRIMINAL VERSUS O DIREITO DE INFORMAÇÃO PELA MÍDIA E A LIBERDADE DE EXPRESSÃO COMO DIREITOS DE PERSONALIDADE
}

\author{
Amanda Budi Fernandes ${ }^{1}$ \\ Ana Luísa de Oliveira Botelho \\ Cacilda Zafaneli ${ }^{3}$ \\ Janaina Pamela Silva Mendes ${ }^{4}$ \\ Luiza Gabriella Berti ${ }^{5}$ \\ Nádia Alessandra da Silva ${ }^{6}$ \\ Raquel Soares Duarte ${ }^{7}$ \\ Fernanda Garcia Velasquez ${ }^{8}$
}

FERNANDES, A. B.; BOTELHO, A. L. de O.; ZAFANELLI, C.; MENDES, J. P. S.; BERTI, L. G.; DA SILVA, N. A.; DUARTE, R. S.; VELASQUEZ, F. G. A digndade da pessoa humana no sistema criminal versus o direito de informação pela mídia e a liberdade de expressão como direitos de personalidade. Rev. Ciênc. Juríd. Soc. UNIPAR. Umuarama. v. 21, n. 1, p. 1-15, jan./jun. 2018.

RESUMO: O presente trabalho propôs uma discussão sobre o poder que a mídia tem diante os indivíduos, a qual pode influenciar em sua subjetividade. Propusemos esclarecer de que forma a mídia atuou e tem atuado na vida das pessoas, colocando um lugar de destaque, infiltrando-se e manipulando quase de forma invisível, mas permanentemente influenciando nas relações. Cabe aos profissionais contribuir para o processo do repensar as relações naturalizadas pela mídia que impõe padrões de vida a serem seguidos, de forma a contribuir para a produção de cidadania vivida de forma livre. O debate desse trabalho é de como essa mídia atua para de certa forma adentrar no Poder Judiciário, incitando a "justiça do povo com as próprias mãos", querendo que a sociedade em geral, julgue, sem ser juiz e não usando diversas vezes da ética, tão falada ultimamente e pouco usada nos meios de comunicação, fazendo com que a sociedade e os seres humanos

\footnotetext{
DOI: $10.25110 /$ rcjs.v21i1.2018.7447

${ }^{1}$ Acadêmica de Direito PIC/UNIPAR

${ }^{2}$ Acadêmica de Direito PIC/UNIPAR

${ }^{3}$ Mestre em Comunicação e Semiótica - PUC/SP

${ }^{4}$ Acadêmica de Direito PIC/UNIPAR

${ }^{5}$ Acadêmica de Direito PIC/UNIPAR

${ }^{6}$ Acadêmica de Psicologia PIC/UNIPAR

${ }^{7}$ Acadêmica de Psicologia PIC/UNIPAR

${ }^{8}$ Mestre em Direito Processual e Cidadania - UNIPAR
} 
entrem em declínio mesmo sem querer.

PALAVRAS-CHAVE: Dignidade; Sistema Criminal; Meios de comunicação; Liberdade de expressão.

\section{INTRODUÇÃO}

No contexto jurídico, o poder da mídia é significativo, visto seu poder incontestável, atuando de modo a levar a sociedade a acreditar que resolver os problemas e fazer justiça sem utilizar o Poder Judiciário é o meio mais fácil e mais plausível, no entanto, não é, pois crimes muito mais graves acontecem quanto àqueles que lhe deram origem.

No contexto social, a mídia busca adentrar no inconsciente das pessoas, usando muitas vezes da subliminariedade e influenciando em sua subjetividade. Influenciam as ações dos seres humanos sem perceber, que acabam por fazer estragos irreparáveis, jamais vistos, causando inconformismo na sociedade.

Para demonstrar o quanto "o poder extraordinário e incontestável exercido pela mídia sobre a população em geral, reflete-se de modo relevante" (PRADO, 1994, apud CAMPOS, 2012), o tópico um apresenta o relato de um caso em que a mídia teve considerável participação e influência no suceder de fatos.

Referido caso, aconteceu na cidade de Umuarama, no interior do estado do Paraná, em que após a prisão de suspeitos confessos do assassinato de um rapaz e estupro de sua noiva, devido ao discurso inflamado do radialista local, que narrava o evento em tempo real, a população enfurecida marcha à delegacia clamando por "justiça" e comentem o linchamento dos suspeitos.

No tópico 2 menciona que é no contexto social que se forma o "ser", existente por meio de suas relações sociais e significados atribuídos a estas, ou seja, um ser histórico-social. O que diferencia o homem de qualquer outro ser no mundo é sua capacidade de ter consciência desse existir, em que se torna capaz de se apropriar da realidade, se colocando a serviço de seus próprios desejos, podendo, consequentemente construir sua história e exercer sua cidadania ( $\mathrm{SCH}$ NEIDER; CASTRO, 1994).

Em diferentes contextos o sujeito, como ser social busca pertencimento e visibilidade. Partindo desse pensar sobre o humano, o presente artigo busca contextualizar sobre o poder que a mídia tem em seus discursos, ditando formas de ser e existir, produzindo uma subjetivação em massa nas relações. Segundo Silva (2002), os discursos midiáticos impedem que os sujeitos pensem, vivam e constituam suas subjetividades de forma ética e livre.

Já o tópico três busca abordar como os meios de comunicação influenciam na vida do cidadão brasileiro, podendo ser essa influência tanto negativa quanto positiva, fato esse que ficará evidenciado no decorrer do presente estudo. 
Ao longo da exposição dos questionamentos e argumentações perceber-se-á que a mídia ocupa um espaço de extrema importância na construção de raciocínios e reflexões criados pela coletividade. Por um lado, alguns creem que ela afasta o obscurantismo, ou seja, o desconhecimento que se tem sobre algo. E, dessa forma, trará o conhecimento necessário para que se busque a efetivação das garantias previstas pela Constituição Federal. Por outro, outros acreditam que os meios de divulgação de informações trazem uma visão distorcida da realidade. Ou melhor, carregam aquilo que é de convicção do emissor. Surgindo, assim, o sensacionalismo midiático, o qual intervém demasiadamente no meio jurídico, em especial nos julgamentos de uma Ação Penal.

\section{RELATO DO CASO}

\subsection{Linchamento em Umuarama}

\subsubsection{Prelúdio:}

Na madrugada do dia 20 de dezembro de 1986, um sábado, Aurico Reis (18), Luiz Iremar Gonfio (19) e Edivaldo Xavier de Almeida (20), sequestraram o fotógrafo Júlio César Jarros (26) e sua noiva, defronte ao portão da casa dela na cidade de Umuarama. Conduzindo- os para fora da cidade, estupraram a moça e mataram a tiros Júlio. Além de estuprada, a jovem foi queimada com bitucas de cigarro em várias partes do corpo e, fingindo-se de morta, livrou-se da morte e dos tiros dos bandidos.

Na manhã de domingo (21), quinze horas após o ocorrido, era noticiado pelas principais emissoras de comunicação da cidade, a prisão dos suspeitos, juntamente com nota de reconhecimento da brilhanturada força policial no processo de investigação e prisão dos suspeitos.

No decorrer do interrogatório, feito no mesmo dia - domingo (21)- os suspeitos confessaram o crime e logo foram conduzidos pelas autoridades ao local que ocorrera o crime para a devida reconstituição. Salienta-se a atitude debochada de um dos suspeitos confessos, Edivaldo Xavier de Almeida (20), que interpelado pela polícia sobre o modo como havia matado o fotógrafo: "Por que não me dão um revólver carregado?" Esse comentário, logo chegou ao conhecimento da população por meio de intenso e inflamado apelos de um popular repórter de uma emissora de rádio local. Foi o estopim para que o fato se tornasse uma comoção generalizada na cidade, chegando ao noticiário nacional e desencadeando um incontrolável desejo de justiça. No entardecer de segunda-feira, 21 de dezembro de 1986, cerca de 2 mil pessoas encontravam-se frente à cadeia de Umuarama,ignorando a resistência policial a fim de tomar os três presos, matando-os a chutes e depois arrastando seus corpos por vários quilômetros ao longo das principais avenidas da cidade, chegando a praça Miguel Rossafa, onde foram 
encharcados com gasolina e atearam fogo diante de uma população ensandecida pelo ódio e fazendo justiça com as próprias mãos.

\subsubsection{Repercussão:}

$\mathrm{O}$ fato ficou conhecido nacionalmente, inclusive se tornando destaque de uma das matérias mais vistas da revista Veja na época. A edição de dezembro de 1.986 trazia que: "Um grupo de pessoas não identificadas marchou para a delegacia pedindo a adesão de todos que encontrava pelo caminho. Ao chegar diante da cadeia, a multidão crescera a tal ponto que os 30 homens da Polícia Militar e a meia dúzia de agentes da Polícia Civil, ali postados para guardar os presos, deram brandos sinais de resistência.

Entregues à própria fúria, os participantes do linchamento amarraram os corpos dos mortos em automóveis e os arrastaram num cortejo que atraiu para as janelas e calçadas mais de 5 mil pessoas. O desfile foi aplaudido. A cada esquina aumentava o coro: "Queima, queima" [...]. "Foi o que se fez em seguida, com a ajuda de 1 litro de gasolina e uma caixa de fósforos, além de alguns pneus para manter as chamas vivas por um tempo".

Passados quase três décadas, os familiares do casal evitam responder questionamentos da mídia. Parentes da vítima, Júlio César Jarros, apenas afirmam que a preocupação, à época, era evitar ver televisão, ler jornais e até ouvir as emissoras de rádio, que transmitiram o fato em tempo real, a fim de preservar, principalmente, os pais do jovem. A então noiva de Júlio César Jarros se formou em Serviço Social e atualmente trabalha com projetos voltados à formação de crianças na capital do Estado.

Após os fatos vários incitadores foram reconhecidos e processados por “arrebatamento" e "vilipêndio a cadáver" em 1.987. Talvez, por não ser sido possível apurar quem realmente matou os presos, ninguém respondeu por homicídio.

Duas décadas após a consumação, sem transitar em julgado a sentença final, extinguiu-se a punibilidade para os réus e o processo foi arquivado.

\section{MÍDIA, QUARTO PODER E FALSA LIBERDADE}

O processo de conscientização implica em uma série de responsabilidades, como por exemplo, a desconstrução das reproduções de relações de dominação/submissão, ligada diretamente ao problema de identidade, tanto pessoal como social, levando as pessoas a assumirem seu papel autêntico como cidadão membro de um grupo e cultura, que tem necessidades como teto, alimentação, saúde, trabalho e também de desenvolvimento pessoal e relações de esperança, identidade e significação social. (MARTIN-BARÓ, 1996).

Porém, é importante refletir sobre a origem das informações que che- 
gam até a população, assim como as relações políticas que governam o país. É preciso contextualizar e desconstruir paradigmas na qual a mídia prega como discurso de verdade.

A mídia é chamada e considerada o Quarto Poder, ou seja, o quarto maior segmento econômico do mundo, sendo a maior fonte de informação e entretenimento que a população possui. O poder de manipulação da mídia, em geral, atua como uma espécie de controle social, que contribui para o processo de massificação da sociedade, resultando num contingente de pessoas que caminham sem opinião própria. Nesse enfrentamento, demanda-se à psicologia que se interrogue a si mesma; convoca-se que ela reflita e analise o quanto os discursos midiáticos impedem que os sujeitos pensem, falem, vivam e constituam suas subjetividades de forma ética e livre. Convida, por fim, a atentar-se para os efeitos que os discursos hierárquicos e totalizantes proferidos pela mídia ocasionam no sujeito (SILVA, 2002).

Segundo o Conselho Federal de Psicologia (2009), nenhum desses elementos faz parte da programação de rotina que as pessoas acessam nos canais de televisão. Assim, não se discutem as questões educacionais, as pesquisas científicas, as políticas públicas para a saúde, as políticas de gestão de trabalho, as relações atuais com os trabalhos, as questões ambientais, os programas de moradia, os projetos de sociedade, as dúvidas, as esperanças. Quase sempre as pessoas se posicionam frente os fatos que as cercam, a partir do modo (ideologia) como são apresentados pela mídia, sobretudo a televisão. Em geral, as mensagens são pré-definidas e premeditadas.

As contribuições de Vygotsky (1998) sobre a aquisição e o desenvolvimento das funções superiores, como a memória, a atenção, o pensamento, a percepção, são de relevância para se entender o impacto das mídias e de seus conteúdos como um dos elementos sociais ativos na produção das subjetividades, nos valores sociais que transmitem, nos modos de agir que difundem, ou seja, na produção dos sujeitos contemporâneos.

Raymond Williams (2007) afirma que alienação é uma palavra bastante antiga e tem circulado entre o Direito, a Filosofia, a Teoria Social e a Psicologia com diferentes significados. Atravessando todos esses significados e sentidos, esses saberes remetem a separação, estranhamento, afastamento, amplamente pregado para designar o modo de funcionamento das relações de trabalho empregadas no capitalismo. A alienação carrega uma conotação de empobrecimento, desqualificação e perda. Alienante é se constituir com qualidade indesejável e parece refletir com precisão o quadro que se tem por parte do sujeito emissor. Para se conseguir alienar uma pessoa, ou seja, subordiná-la, é preciso negar (mesmo que indiretamente), a ela a possibilidade de ser que se manifesta em comunicar sua opinião, expressar seu pensamento. O original e o fantástico do ser humano 
é dizer a palavra, apresentar sua opinião, expressar seu pensamento. É nisso que o ser humano se explicita, se desdobra.

Para Marilena Chauí, o campo democrático é constituído para a ampliação e pelo reconhecimento dos direitos humanos. Assim sendo, a cidadania apresenta a necessidade de reflexão entre a distância estabelecida entre uma situação de privilégios e carência de benefícios, o que caracteriza muitas pessoas ao redor do mundo. Onde não há direitos, continua Marilena Chauí, não há sujeitos. Onde não há reconhecimento de sujeitos, estes são tratados como coisas. Chauí considera que a estrutura oligárquica e autoritária da sociedade brasileira bloqueia a instituição do Estado democrático e da cidadania.

As questões de alienação e cidadania não podem, portanto, estar separadas do contexto que as precede como condição de existência, e precisam ser recuperadas como forças mais ou menos intervenientes na produção dos sujeitos contemporâneos. Trata-se então de recuperar a ideia de sujeitos autônomos, responsáveis e comprometidos com suas vidas e com as de seus pares, para além de uma natureza boa ou má, ampliando-a para a construção de novas condições para as sociabilidades humanas com a vida em meio a comunicações democratizadas (CHAUÍ, 2006).

A despeito da problematização sobre liberdade e falsa liberdade, o presente estudo, pretende aqui, contextualizar a visão de homem a qual se refere.

Para Schneider e Castro (1994), o sujeito existe por meio de suas relações sociais e os significados atribuídos a essas relações, tornando-se um Ser histórico-social. Esse ser, posto no mundo, passa a desenvolver suas subjetividades como produto de suas relações, desde o momento em que passa a diferenciar-se dos outros num processo de infinitas possibilidades e de essencializar-se e formar sua personalidade.

Por meio das relações, inserindo-se em grupos sociais além do familiar, que lhe possibilita outras informações, valores, regras morais, pensar sobre seu eu, se apropriando de seu ser, se vendo pertencente a um espaço, como produto de sua historicidade.

A pessoa livre compreende que qualquer ação é uma escolha, e ao fazer essa escolha, define suas possibilidades existenciais. Essas escolhas se darão em seu contexto de possibilidades, o que prega o Existencialismo, corrente filosófica de Jean-Paul Sartre, a chamada liberdade situada (SARTRE, 1987)

A liberdade, a qual se refere o presente trabalho, seria o que, para Arendt, em termos conceituais, passar da liberdade filosófica à liberdade política. Para ela, (ARENDT, 2005) o sentido da política é a liberdade, liberdade de ação. "“...] ação e política, entre todas as capacidades e potencialidades da vida humana, são as únicas coisas que não poderíamos sequer conceber sem ao menos admitir a existência da liberdade [...]"' (ARENDT, 2005, p. 191). 
Segundo Coimbra (2000), a produção das subjetividades hoje em dia, tenta encaixar as pessoas nos padrões de produção e consumismo do capitalismo a todo e qualquer custo, pois assim o Estado será provedor de Direitos, depositando a responsabilidade no próprio sujeito, instigando-o ao individualismo e à cultura da meritocracia, causando nele sofrimento e angústia, além da violação dos direitos e a sua marginalização.

Portanto, a tal liberdade pode ser não tão livre assim, uma vez que há um padrão a ser seguido imposto pelo capitalismo e as mídias. A liberdade de escolher entre uma marca ou outra, entre ser de um jeito ou de outro, é apresentada de forma falsa de ser e existir.

\section{O PODER SUBLIMINAR DA MÍDIA E A VIOLAÇÃO DOS DIREITOS HUMANOS}

Homologada no ano de 1948, a Declaração Universal de Direitos Humanos é um marco histórico para a civilização humana. Ela foi uma das pioneiras na internacionalização dos direitos humanos e, por sua vez, corroborou significantemente para a criação de tratados e convenções que buscam efetivar essas garantias.

Em seu artigo 19, a referida declaração aponta: "todo o indivíduo tem direito à liberdade de opinião e de expressão, o que implica o direito de não ser inquietado pelas suas opiniões e o de procurar, receber e difundir, sem consideração de fronteiras, informações e ideias por qualquer meio de expressão". Portanto, segundo o artigo mencionado a comunicação é um direito a ser reivindicado, influenciando, assim, de maneira direta na preservação ou recusa de outros direitos.

A mídia, nesse contexto, possui um forte poder de persuasão e pode instigar a maioria das pessoas no modo de buscar uma melhor qualidade de vida por meio da saúde, educação, moradia, etc., contribuindo, respectivamente, para a construção de uma cultura com base no respeito aos direitos humanos. Contudo, pode também exercer influência de forma a proporcionar os mecanismos necessários para se arquitetar uma coletividade respaldada no desrespeito evidenciando-se por meio do preconceito e opressão para com o outro.

A imparcialidade na imprensa é um mito, porque a opinião pessoal do interlocutor (repórter) está embutida no texto (...) Caso haja um interesse externo a ser atendido na reportagem, um pedido do departamento comercial ou da própria direção, a parcialidade é ainda maior e o texto torna-se deveras tendencioso. Isso não acontece exclusivamente nos jornais impressos, mas também no rádio e 
na televisão. A opinião indireta, nos textos jornalísticos noticiosos, acaba conduzindo, com mais força do que os editoriais, a opinião pública de determinadas classes sociais e intelectuais. (MICHALIZEN, 2012, p.47)

A mídia brasileira demonstra ser uma das maiores violadoras dos direitos humanos. Uma análise mais profunda e sistemática acerca do assunto mostra quanto é preocupante a realidade dos meios de comunicação no Brasil. Destacam-se

[...] dois exemplos são emblemáticos: os programas de auditório que exploram conflitos pessoais e abusam da exposição das mazelas de pessoas em situação de vulnerabilidade psicológica e social; e os programas policiais que violam direitos de crianças e adolescentes, criminalizam a pobreza, invadem domicílios e desrespeitam, de todas as formas, a dignidade humana. Em síntese, a mídia brasileira, de um modo geral, tem sido criminosa e irresponsável pela infinidade flagrante de reforços de intolerância e violência. (INTERVOZES, 2013).

Por muitas vezes, a transgressão não é incitada de forma explícita, no entanto, a conduta se manifesta na omissão em relação à luta pela dignidade humana.

À vista disso, nenhuma maneira é mais eficaz do que os meios de comunicação (em suas diversas formas, como: internet, jornal, televisão, revistas, etc.) para a propagação de ideais, sendo eles positivos ou negativos.

$O$ fato é que os meios de comunicação são relevantes para a vida do homem, uma vez que, além de informar resultam na forma pela qual cada indivíduo receberá esses dados, e, consequentemente, o influenciará no comportamento em sociedade. E ainda atuar acerca da estruturação e entendimento da realidade nacional, haja vista que transmitem fatos e posicionamentos por meio da escrita, imagens e sons, os quais refletem uma espécie de controle social quando ditam modismos, ideologias e outras séries de manifestações que intervém na opinião pública.

Todavia, além de intervir na opinião pública, a mídia, que é tão emblemática no dia a dia das pessoas, dissemina sua vontade para o meio jurídico brasileiro, mais especificamente para o sistema jurídico processual penal no que tange à reação da população frente aos crimes.

Pode-se observar que a mídia exerce uma espécie de quarto poder, e isso devido ao fato de ela ser a maior fonte de informação e entretenimento já 
encontrada. Observa-se também, que essa seria outra espécie de poder condenatório, uma verdadeira sentenciadora de casos, estando, geralmente, de acordo com aquilo que os meios midiáticos defendem e propagam, tendo em vista sua forte manipulação em relação à população em geral. Assim,

O poder extraordinário e incontestável exercido pela mídia sobre a população em geral (...) reflete-se de modo relevante, no processo penal, quando atua diretamente sobre a convicção do juiz, intentando formá-la não mais com base nas provas dos autos, obtidas com a segurança do contraditório e da ampla defesa, porém a partir da conclusão amiúde precipitada a que chegam órgãos informativos, de tal sorte que o secular princípio da imparcialidade resta afetado, às vezes até mesmo sem que o julgador se dê conta. (PRADO, 1994, p. 106 apud CAMPOS, 2012, p. 11)

O poder condenatório da mídia é representado não somente por ser uma sentenciadora de casos, mas também na transformação que tem proporcionado à população ao longo dos anos. Um exemplo disso é como os meios de comunicação passaram a dar um grande enfoque nos assuntos relacionados à violência, gerando comoção e revolta nas pessoas que encontram nesses meios uma válvula na qual possam se reconfortar. $\mathrm{O}$ que era antes repudiado, como a pena de morte, linchamentos e outras formas de execução da pena que ferem demasiadamente os direitos humanos, hoje são aclamados pelo povo a ponto de fazerem parte da estrutura do Código Penal.

É certo que o próprio ser humano trata de formas diferenciadas aquele que está sendo acusado de praticar algum crime. No entanto, a mídia explora o sentimento de crueldade da maneira mais sórdida e sensacionalista possível, influenciando o processo penal brasileiro com uma carga extremamente negativa. Defendendo a exclusão da presunção da inocência, o devido processo legal e princípios democráticos que demoraram séculos para serem conquistados e colocados em prática, mas atualmente se veem ameaçados por uma suposta justiça que corrobora para os males da sociedade.

As palavras de Felipe Pena demonstram mais claramente os trechos fundamentados: (2007, p. 113)

Os julgamentos são influenciados pela formação e, também pelo que os meios de co- municação nos apresentam como verdade. Somos cruéis em nossos julgamentos. $\mathrm{Na}$ maioria das vezes, esquecemos que eles são mediados. Se não forem pela imprensa, podem ser pelos nossos pró- 
prios preconceitos, pelo inconsciente ou pela linguagem. [...] os maniqueísmos se apresentam e o veredicto se resume à velha luta entre o bem e o mal. Só que os indivíduos são muito mais complexos do que isso.

Assim como as da autora Ana Lúcia Menezes Vieira:

A valorização da violência, o interesse pelo crime e pela justiça penal é uma prática enraizada na mídia, que encontra seu melhor representante no jornalismo sensacionalista. Utilizando-se de um modo próprio da linguagem discursiva, ágil, coloquial e do impacto da imagem, promove uma banalização e espetacularização da violência.

Por conseguinte, geralmente, o que tem se observado, é que o devido processo legal e a presunção a inocência estão sendo deixados de lado por conta da forte pressão midiática em relação aos supostos crimes. Essa pressão influencia a população como um todo especialmente, naqueles que são encarregados de apurar os fatos que são levados ao seu julgamento, como os juízes, delegados, investigadores, promotores etc.

A priori, todos são parciais, pois a emotividade está entremeada na vida de cada um. Sendo assim, é quase impossível o profissional da comunicação ser imparcial, embora seja isso que a população espera dele.

Claramente não se fala na tentativa de desrespeitar a liberdade de expressão, até porque, em qualquer país que se nomeie como democrático, os meios de comunicação devem ser respaldados pela livre manifestação de pensamento. O que se propõe é que sejam responsabilizados aqueles que cometem abusos em se tratando desse princípio.

Também é importante frisar que algumas redações mantêm regras que devem ser seguidas por seus jornalistas, sendo elas preocupadas com a verdade que será transmitida para seu leitor, bem como o respeito à persecução penal.

Muitos profissionais têm a consciência de que são os "porta-vozes" das informações que surgem segundo após segundo ao redor do mundo, e que, por consequência, sua responsabilidade é aumentada devido ao fato que às notícias devem ser respaldadas seguindo as normas constitucionais, sociais e morais existentes.

Logo, conclui-se que sempre deverá haver uma harmonização entre a liberdade de expressão e as garantias individuais do acusado, haja vista que ambos fazem parte dos princípios estruturantes do Estado Democrático de Direito e desempenham significativo papel na luta pela preservação dos direitos do homem em sociedade. 
E, por fim, o que se busca é uma imprensa constituída por profissionais sérios e que adotam como regra maior a ética, buscando a todo o momento transmitir a verdade e empenhada na edificação de uma imprensa livre e nivelada pela democracia, construindo notícias pelo povo e para o povo. Logo, afastando os interesses políticos próprios que a cada vez mais assombram a preservação de um país sem amarras.

Em entrevista com a professora Sônia Moro - mestre e doutora em Comunicação e Semiótica, ela esclarece que, geralmente, a interpretação dos fatos depende muito dos estímulos internos de quem recebe a informação. As reportagens jornalísticas, por exemplo, fazem com que esses encorajamentos sejam aguçados de acordo com as vivências e emoções de cada pessoa, pois cada uma traz consigo uma bagagem, um repertório e, a manipulação pode se fazer presente.

Algumas pessoas, por não serem intelectualmente bem preparadas, podem confundir mais facilmente o significado das palavras do repórter ou potencializar emocionalmente, fazendo com que o sentimento sobrepuje a razão, quando da interpretação dos fatos jornalísticos.

Quando se recebe uma mensagem - auditiva ou não - frequentemente acontece a sua percepção subliminar, incitando um comportamento inverso. Exemplo: alguns programas de televisão, rádio, jornais, etc., exigem reportagens de acidentes, muitas vezes expondo as vítimas e até os familiares, levando as pessoas a tirar fotos, fazer vídeos e postar nas redes sociais, o que é considerado crime.

As mensagens subliminares estão, quase sempre, embutidas nos processos de comunicação, e, na maioria das vezes isso não é percebido - conscientemente - pelo ouvinte ou telespectador. Há uma intenção premeditada das emissoras de que isso aconteça, mas sempre de forma indireta, implícita, camuflada. Há sempre um motivo que justifica esse comportamento dos meios de comunicação e, em geral é econômico. E isso, muitas vezes incita na população a famosa "justiça com as próprias mãos", causando danos irreparáveis.

A cada dia que passa, parece que o descaso do poder público para com a população, também neste quesito, fica cada vez mais assoberbado, ou seja, o dever de proteção e segurança que deveria ser garantido por políticas públicas estão muito aquém das necessidades das pessoas, que, muitas vezes ficam enclausuradas dentro de suas próprias casas, com medo de sair às ruas. Ademais, a falta de conhecimento das pessoas sobre seus próprios direitos, em muito contribui para que a situação de medo e insegurança cresça cada vez mais em nosso país. Isto quer dizer que a ética - sempre tão enaltecida pelos filósofos e pelos próprios políticos - está muito aquém do necessário para que cada um de nós consiga sobreviver sem ser corrompido. 


\section{CONSIDERAÇÕES FINAIS}

Infere-se do presente estudo que o poder influenciador da mídia é tamanho que levou a situação descrita no tópico um "relato do caso", já que como enaltecido, a inflamação despertada pelas emissoras locais e nacionais da época foi capaz de instigar um senso de justiça rijo na população que provocou o linchamento; delito este tão desumano e hostil quanto àquele que se vislumbrava rebater.

A repercussão representada pelas 2 mil pessoas que invadiram a delegacia e ignoraram a resistência policial demonstra que os noticiários aviventaram o estupro e o homicídio ocorrido no dia 20 de dezembro de 1986 de tal maneira que encorajou indivíduos moralmente idôneos a praticarem um crime bárbaro.

No tópico 2, portanto, o poder de manipulação da mídia em geral atua como uma espécie de controle social, que contribui para o processo de massificação da sociedade, resultando num contingente de pessoas que caminham com discursos pré-estabelecidos. Diante disso, busca-se uma reflexão do que essa mídia traz para a produção da subjetividade das pessoas, implicando no sujeito o desejo de atingir o padrão socialmente instituído, quanto uma falsa ideia de liberdade. Este processo reforça a culpabilização individual de pessoas que não alcançam seus objetivos, que não atingem um ideal, contribuindo com a exclusão social.

Contudo, cabe tanto para os profissionais da Psicologia como das áreas do Direito, fazer com que as pessoas problematizem sobre tais relações subjetivadas pela mídia, fazendo parte do processo de conscientização implicando em uma série de responsabilidades, como por exemplo, a desconstrução das reproduções de relações de dominação/submissão, ligada diretamente ao problema de identidade tanto pessoal como social, levando as pessoas a assumirem seu papel autêntico como cidadão.

Por fim, no terceiro e último tópico o conteúdo desenvolvido destaca os dois lados da mídia brasileira, podendo ela influenciar o ser humano tanto de forma positiva quanto negativa. Positivamente, seriam os meios de comunicação a favor do corpo social, ou seja, atuando de modo que grande parte das pessoas mantenha-se esclarecida, buscando incessantemente a efetivação dos seus direitos, entre eles a educação, saúde, segurança, etc.

No entanto, observa-se que esse não é o papel que os meios de comunicação têm potencializado. Pelo contrário, muitas das vezes são os maiores violadores dos direitos humanos, incitam a violência por meio de programas policiais e de auditório. Se não bastasse, persuadem aqueles que estão encarregados de apurarem os fatos supostamente criminosos e levá-los a julgamento, como os juízes, promotores de justiça, delegados, etc. 
Além disso, o empenho por traçar um palco de selvageria por todo o país somente faz surgir no povo um sentimento de insatisfação, o qual, na maioria das vezes, tem-se demonstrado pelo clamor em adotar métodos retrógrados de tortura, assim como a pena de morte.

Entretanto, verifica-se que esse sensacionalismo midiático pode ser rebatido com um jornalismo ético, voltado para a imparcialidade do jornalista. E, que possui como maior objetivo manter a liberdade de expressão, bem como o devido processo legal, a presunção da inocência e outros princípios democráticos fundamentais para a vida em sociedade.

\section{REFERÊNCIAS:}

ARENDT, H. O que é política? Rio de Janeiro: Bertrand Brasil, 1998. 240 p.

COIMBRA, C. M. B. Psicologia, Direitos Humanos e Neoliberalismo. Psicologia Política, Rio de Janeiro, p. 139-148, maio/julho, 2000. Disponível em: $<$ http://www.fafich.ufmg.br/ psicopol/psicopol/artigos_pub/artigo_9.pdf>. Acesso em: 23 set. 2016.

CONSELHO FEDERAL DE PSICOLOGIA. Mídia e psicologia: produção de subjetividade e coletividade. 2.ed. / Conselho Federal de Psicologia. - Brasília : Conselho Federal de Psicologia, 2009. 392 p.

CHAUÍ, M. Simulacro e poder: uma análise da mídia. São Paulo: Perseu Abramo, 2006.

DECLARAÇÃO UNIVERSAL DOS DIREITOS HUMANOS. Organização das Nações Unidas (ONU), 1948. INTERVOZES. Mídia e direitos humanos: um debate necessário. Disponível em: <http://www.cartacapital.com.br/blogs/intervozes/midia-e-direitos-humanos-um-debate-necessario-9408.html>. Acesso em: 21 jul. 2016.

LOBÃO, T. O linchamento em Umuarama. Lobservando, publicado em: 22 de dezembro de 2009. Disponível em: <http://www.lobservando.com/2009/12/o-linchamento-em-umuarama.html>. Acesso em: 20 jul. 2016.

MARTIN-BARÓ, I. O papel do psicólogo. Estudos de Psicologia. v. 2, n. 1, p. 7-27, 1996. Disponível em: <http://www.scielo.br/pdf/epsic/v2n1/a02v2n1. pdf>. Acesso em: 05 abr. 2016.

MICHALIZEN, F. A influência da mídia no processo penal brasileiro e seus 
reflexos no julgamento dos crimes. Disponível em: <http://www.femparpr.org. br/monografias/upload_monografias/fernando\%20rafael\%20pallu\%20michalizen.pdf.. Acesso em: 18 jul. 2016.

PENA, F. Teoria do jornalismo. São Paulo: Contexto, 2007. p.113.

PRADO, G. L. M. Opinião pública e processo penal, Boletim Legislativo Adcoas, Rio de Janeiro, ano 28, n. 30, out 1994. p. 106. In: CAMPOS, MARCOANTÔNIO MAGALHÃES. A influência da mídia no processo penal. Disponível em: $<$ http://www.emerj.tjrj.jus.br/paginas/trabalhos_conclusao/1semestre2012/ trabalhos_12012/marcoantoniocampo s.pdf $>$. Acesso em: 21 jul. 2016.

SARTRE, J. P. O existencialismo é um humanismo. São Paulo: Nova Cultural, 1987.

SCARPARO, H.; GUARESCHI, N. Psicologia social comunitária e formação profissional. Psicologia \& Sociedade. Porto Alegre, v. 19, n. 2, p. 100-108, 2007.

VYGOTSKY, L. S. Formação social da mente. São Paulo: Martins Fontes, 1998.

SCHENEIDER, D. R.; CASTRO, D. J. Contribuições da psicologia existencialista para a psicologia social crítica. Cadernos de Psicologia, Rio de Janeiro: Instituto de Psicologia, v. 8, n. 1, s/p., 1994.

SILVA. E. F. G. O impacto e a influência da mídia sobre a produção da subjetividade. Ipojuca-Pernambuco, 2002. Disponível em: <http://www.abrapso.org. $\mathrm{br} /$ siteprincipal/images/Anais_XVENABRAPSO/447.\%20o\%20impacto $\% 20$ e $\% 20 \mathrm{a} \% 2$ 0influ $\%$ CAncia $\% 20 \mathrm{da} \% 20 \mathrm{~m} \%$ CDdia.pdf $>$. Acesso em: 15 maio 2016.

VIEIRA, A. L. M. Processo penal e mídia. São Paulo: Revista dos Tribunais, 2003.

\section{HUMAN DIGNITY IN THE CRIMINAL SYSTEM VERSUS THE MEDIA'S RIGHT TO INFORMATION AND THE FREEDOM OF SPEECH AS PERSONALITY RIGHTS}

ABSTRACT: This study presents a discussion about the power of the media against individuals, which can influence their subjectivity. The authors propose to clarify how the media acts and has acted in the lives of people, infiltrating 
and manipulating in an almost stealth manner, but still influencing relationships. It is up to the media professionals to contribute in the process of rethinking the relationships naturalized by the media that impose living standards to be followed in order to contribute towards producing citizenship to be lived freely. The discussion presented in this paper is on how the media works its way into the Judiciary Power, encouraging "justice with their own hands", expecting society in general to judge, without being a judge and not always ethically, which has been so widely spoken and so rarely used by the media, resulting in the unwilling decline of society and human beings.

KEYWORDS: Dignity; Criminal System; Media; Freedom of Speech.

\section{DIGNIDAD DE LA PERSONA HUMANA EN EL SISTEMA CRIMINAL VERSUS EL DERECHO DE INFORMACIÓN POR LOS MEDIOS DE COMUNICACIÓN Y LA LIBERTAD DE EXPRESIÓN COMO DERECHOS DE PERSONALIDAD}

RESUMEN: El presente estudio propone una discusión sobre el poder que los medios de comunicación tienen delante a los individuos, y cómo puede influenciar en su subjetividad. Nos propusimos aclarar de qué forma los medios de comunicación actuaron y han actuado en la vida de las personas, poniendo lugar de destaque, infiltrándose y manipulando casi de forma invisible, pero permanentemente influenciando en las relaciones. Cabe a los profesionales contribuir para el proceso del repensar las relaciones naturalizadas por los medios de comunicación que impone estándares de vida a ser seguidos, de forma a contribuir para la producción de ciudadanía vivida de forma libre. El debate de ese estudio es de como los medios de comunicación actúan para de cierta forma adentrar en el Poder Judiciario, incitando la "justicia del pueblo con las propias manos", queriendo que la sociedad en general juzgue, sin ser juez y no utilizando la ética, tan hablada últimamente y poco usada en los medios de comunicación, haciendo con que la sociedad y los seres humanos entren en declive mismo sin querer.

PALABRAS CLAVE: Dignidad; Sistema criminal; Medios de comunicación; Libertad de expresión. 